\title{
Experience with Electricity Market Test Suite: Students versus Computational Agents
}

\author{
Quynh Chi Trinh, Marcelo Saguan, and Leonardo Meeus
}

This is the post-print version of: Quynh Chi Trinh, Marcelo Saguan and Leonardo Meeus, "Experience with Electricity Market Test Suite: Students Versus Computational Agents", IEEE Transactions on Power Systems, Volume 28, Number 1, 2013, pp. 112-120 - http://hdl.handle.net/1814/26378

(c) 2013 IEEE. Personal use of this material is permitted. Permission from IEEE must be obtained for all other users, including reprinting/ republishing this material for advertising or promotional purposes, creating new collective works for resale or redistribution to servers or lists, or reuse of any copyrighted components of this work in other works. 


\title{
Experience with Electricity Market Test Suite: Students versus Computational Agents
}

\author{
Quynh Chi Trinh ${ }^{*}$, Marcelo Saguan ${ }^{\#}$, and Leonardo Meeus ${ }^{\S}$
}

\begin{abstract}
This paper applies two experimental economics methods (i.e. agent-based modeling and laboratory experiment) to a market test suite that is based on a fictional European wholesale electricity market. Quantitative results of generators' strategic behavior in this market context are separated between generators played by human subjects (i.e. master students) in a laboratory experiment and generators represented by computational agents in an agent-based model. The behavior is measured through offers that students or agents make when participating in the electricity trading auction and the market outcomes under both methods are discussed in order to illustrate the difference between the behavior of human and computational agents. The paper also identifies the improvements that would need to be made to the market test suite to allow for a more conclusive comparison in future experiments.
\end{abstract}

Index Terms - Electricity market, experimental economics, simulation game, agent- based modeling, strategic behavior.

\section{INTRODUCTION}

E xperience with electricity markets worldwide provides evidence that market design affects market performance [1]. Testing the efficiency of market design in the real world can be costly, so it is desirable to simulate market behavior to anticipate problems before the implementation of new designs [2].

Game theory (or equilibrium modeling) [3]-[8] has been the dominant approach for simulating market behavior. This approach is however limited in capturing the dynamics of the liberalized electricity market [9]. Therefore, more flexible models coming from experimental and computational economics are increasingly used. The computational method (i.e. agentbased modeling [10]-[18]) is strong in studying systems that are complex, while laboratory experiments [19]-[22] could provide information on how people behave and learn in a given environment. Most studies consider the behavior of certain players in a particular market design [11], [12] or compare the impact of design options on specific players or the system as a whole [13], [14]. Laboratory experiments study the behavior of human subjects in a controlled market environment and they have also been used in university laboratories for educational purposes [19], [20].

\footnotetext{
* Q.C. Trinh is with the Division of Electric Energy and Computer Architectures ESAT-ELECTA, University of Leuven (K.U. Leuven), Kasteelpark Arenberg 10 box 2445 / B-3001 Leuven / Belgium (e-mail: quynhchi.trinh@esat.kuleuven.be) \# M. Saguan is with Microeconomix, 5 rue du Quatre Septembre / 75002 Paris / France (email: marcelo.saguan@microeconomix.com)

$\S$ L. Meeus is with Florence School of Regulation, European University Institute, Villa Malafrasca, Via Boccaccio 151 / I - 50133 Firenze (FI) / Italy (email: leonardo.meeus@eui.eu)
}

Together with the rise of new market study methods, several researchers started comparing these experimental economics approaches with the traditional game theoretic approaches. For example, [23] uses a simple 3 nodes market to compare the result of an Equilibrium Program with Equilibrium Constraint (EPEC) model with that of a Reinforcement Learning agentbased model. In [24], a pool market with inelastic and constant loads is the environment for comparing Nash equilibrium analysis and agent-based modeling using Q-learning.

The contribution of this paper is to provide an initial comparison of computational agent-based and laboratory experiments with a market test suite that is based on a fictional European electricity market. The approach used does not allow us to be conclusive, but the results illustrate that this is a promising line of research that merits further investigation, and we give some recommendations for this.

The rest of the paper is organized as follows. Section II briefly presents and characterizes the two approaches, as well as identifies their advantages and limitations. Section III describes the case study and settings by which the two approaches are applied. Quantitative results of the computational agent-based models and lab experiments are presented in section IV. Based on the results, detailed analysis and comparison on the experiments' and models' settings are discussed in section $\mathrm{V}$. Finally, section VI concludes the paper.

\section{ChARACTERIZING THE TWO APPROACHES}

In this section, the laboratory experiment and agent-based modeling are presented together with their advantages and limitations.

\section{A. Laboratory experiments}

Laboratory experiments - or in this paper, laboratory simulation games - are applications of experimental economics which have human subjects as agents to study economics theories and systems. The computerization of experiments in recent years has made this method sufficiently affordable to be performed in universities, serving educational purposes. Also, it facilitates tests with more complicated interactions between subjects and more sophisticated simulated economic structures than "paper-and-pencil" experiments used previously [25]. Examples of simulation games in universities about electricity markets include [19] and [20]. These laboratory games usually focus on competitive trading auctions in the electricity market. Students typically take the role of generators which have tools for calculating their electricity generation costs so that they can formulate their bids. By playing the game repeatedly, students obtain practical experience on how trading in a electricity market works and how bids and offers should be made.

In laboratory experiments, the behavior of human subjects can be observed in a controlled environment, including their learning 
process over time. For testing impacts of an environment (e.g. a certain kind of market design) on relevant participants, these observations are extremely meaningful. However, objections to this method also relate to the nature of human subjects. Humans are complicated in term of motivation, cognition, preference and experience, and so cautious control is required when setting the experiment. Laboratory simulation games are also constrained by time and number of subjects, which limit their repetition and diversity as it actually happens in the real world.

\section{B. Agent-based modeling}

In models using agent-based modeling, agents are defined to "think", "act" and "react" and to be "goal-oriented" all by themselves without interference from modelers during the evolution of the system. These features of agents are made possible through a "brain" that modelers assign to agents when developing the model. The "brain" is a learning algorithm. Learning algorithms have been derived from disciplines such as psychology (Roth-Erev reinforcement learning [26]), biology (genetic algorithms) or computer science (Q-learning). One example of agent-based models is presented in [14] where the problem of congestion is dealt with by using generator agents that apply Q-learning. Another example can be found in [15], where interrelated electricity markets (balancing, day-ahead and $\mathrm{CO} 2$ emission markets) are subjected to the strategic behavior of generator agents.

Computational agents are less complicated to work with than human subjects, but the model set-up is decided initially by modelers which can be biased in their choices. More importantly, computational agents are criticized for not being able to simulate human cognitive characteristics, such as subjective preferences, perception and bounded rationality [27], [28], which have a great influence in the human decision-making process in reality.

\section{CASE OF THE ELECTRICITY MARKET TO APPLY THE TWO APPROACHES}

In this section, we first describe the market setting in which the two approaches are compared and then describe how the approaches have applied in this context.

\section{A. Market setting inspired by the European electricity market}

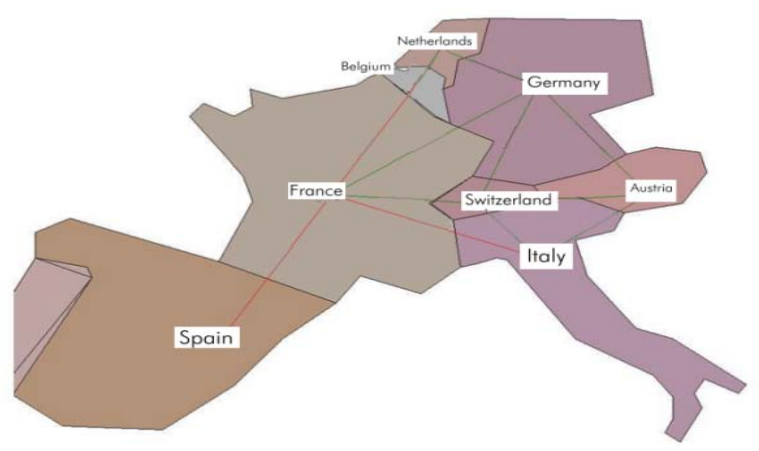

Fig. 1. European electricity market context for simulation and modeling

The market context that has been chosen is defined as the interconnected market between eight European countries, namely France, Spain, Belgium, Germany, Switzerland, Italy, the Netherlands and Austria. Each country is considered as a node with a fixed aggregated demand curve. Nodes are connected with each other by transmission lines with limited capacity and equal impedances for each line. Transmission line capacities are set up in order to create congestion so that the learning experience includes the impact of congestion on the market. Fig. 1 describes the network and indicates which lines interconnect with which countries (nodes).

TABLE I

LIST OF GENERATORS

\begin{tabular}{c|l|l}
\hline No. & Name & \multicolumn{1}{c}{ Country } \\
\hline 1 & Gen1 & Italy \\
\hline 2 & Gen2 & Switzerland \\
\hline 3 & Gen3 & Germany, Austria, Netherlands \\
\hline 4 & Gen4 & France, Germany, Austria \\
\hline 5 & Gen5 & Italy \\
\hline 6 & Gen6 & France, Belgium, Netherlands \\
\hline 7 & Gen7 & Germany \\
\hline 8 & Gen8 & France, Spain, Italy \\
\hline 9 & Gen9 & Spain, Italy \\
\hline 10 & Gen10 & Netherlands \\
\hline 11 & Gen11 & Spain \\
\hline 12 & Gen12 & Belgium, Netherlands \\
\hline 13 & Gen13 & Germany, Austria \\
\hline 14 & Gen14 & Germany
\end{tabular}

There are 14 fictive generators active in this interconnected market. As the demand side is considered fixed, the market participants that are modeled or play are these 14 market players (the market operator is not considered as a player). One generator can participate in more than one node and in each node his generation is characterized by a given marginal cost curve and a maximum capacity of electricity production. That is to say, one generator can have different cost structures at different nodes. Names of 14 players and their active nodes are listed in Table I.

TABLE II

GenERATORS' MARKET SHARES (\%) AND MARKETS' HHI

\begin{tabular}{c|c|c|c|c|c|c|c|c}
\hline Name & AT & BE & DE & FR & IT & NL & ES & CH \\
\hline Gen1 & & & & & 4 & & & \\
\hline Gen2 & & & & & & & & 50 \\
\hline Gen3 & 40 & & 27 & & & 10 & & \\
\hline Gen4 & 26 & & 8 & 88 & & & & \\
\hline Gen5 & & & & & 11 & & & \\
\hline Gen6 & & 74 & & 2 & & 25 & & \\
\hline Gen7 & & & 14 & & & & & \\
\hline Gen8 & & & & 1 & 9 & & 46 & \\
\hline Gen9 & & & & & 67 & & 6 & \\
\hline Gen10 & & & & & & 19 & & \\
\hline Gen11 & & & & & & & 45 & \\
\hline Gen12 & & 24 & & & & 40 & & \\
\hline Gen13 & 20 & & 33 & & & & & \\
\hline Gen14 & & & 15 & & & & & \\
\hline Others & 14 & 2 & 3 & 9 & 9 & 6 & 3 & 50 \\
\hline HHI & $\mathbf{2 8 7 2}$ & $\mathbf{6 0 5 6}$ & $\mathbf{2 3 1 2}$ & $\mathbf{7 8 3 0}$ & $\mathbf{4 7 8 8}$ & $\mathbf{2 7 2 2}$ & $\mathbf{4 1 8 6}$ & $\mathbf{5 0 0 0}$ \\
\hline
\end{tabular}

The set of generators and their cost functions have been chosen to represent a situation with strongly concentrated national electricity markets. The $\mathrm{HHI}^{1}$ of each market is provided

1 HHI (Herfindahl-Hirschmann Index) is a standard measure of market concentration, equaling the sum of squares of the market shares of each generator. 
in Table II. A market with an HHI value above 1800 is considered as a highly concentrated market. As can be seen in Table II, all nodes have HHI values in excess of 2000. This is also the situation in most actual electricity markets, as indicated in the Energy Sector Inquiry [29].

Trading is assumed to be concentrated in an hourly day-ahead auction. Offers from generators at each node are submitted to the auctioneer (i.e. market operator) which then calculates the market outcomes, including locational marginal price ${ }^{2}$, the resulting trade volumes, transmission flows and network congestion.

\section{B. The KU Leuven lab game}

The game has been developed for the first master year of the subject of energy in the engineering department of the KU Leuven. Providing that students are unfamiliar with electricity markets, the game helps them to understand better the market complexities.

The market is set up as described in the previous section. Students play the role of generators who make hourly offers in the auction by submitting their supply curves for the next day's delivery to the market operator. Based on a fixed marginal cost curve of their own generation (cost of supply in function of the volume) in each country they are active, students set up a offer curve which they believe would maximize their profit. Setting up a "good" offer curve implies that students understand the impact of network congestion on prices and take advantage of their market power. Naturally, it is hard for students to understand these issues from the start, but the game consists of several sessions (around 10) to help students learn from their previous results and improve their strategic behavior gradually. For the first session, students are asked to offer at their marginal costs, which then functions as the benchmark for their strategic behavior in the following sessions. After the first 5 sessions, when students are familiar with the game, realize their optimal strategy and observe some phenomena such as there being a very high price on the market even when their quantity offers are not fully accepted, they are introduced to the concepts of market power and congestion. This instruction re-motivates students with new interesting concepts and also speeds up the students' learning in the next 5 rounds. Students' motivation therefore is maintained and their results converge in about 10 rounds.

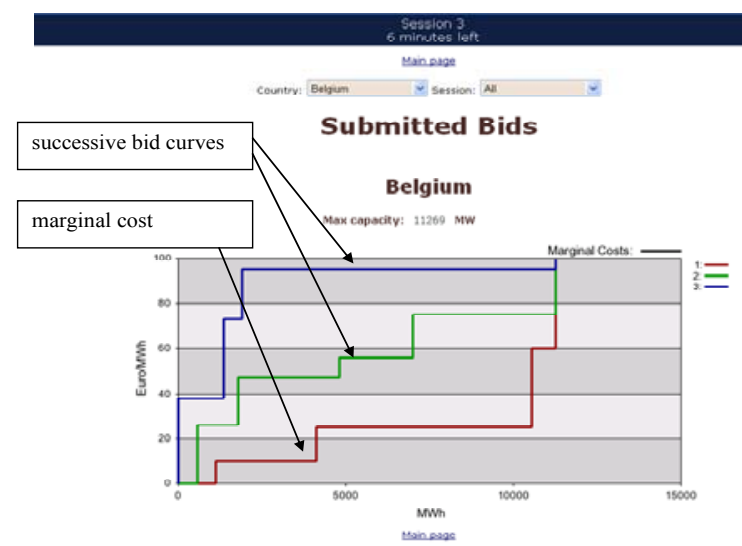

${ }^{2}$ For a detailed explanation about the calculation of the locational marginal price,
see [30].

\section{Fig. 2. Supply offering curves vs. marginal cost curve}

In the game, students' offers are submitted via a web browser in the form of 10 price limit-volume combinations per country per session. These offers are turned into a step function as illustrated in Fig. 2. Offers after submission are then put into the auction clearing function ${ }^{3}$, together with demand curves, in order to determine which offers should be accepted to maximize the total social surplus under the constraint of available transmission capacities. After solving the optimization, the market auctioneer returns the market outcomes to the students, including the market clearing prices at each node, aggregated demand curves, and their accepted production volumes (private information). Based on these results, students get insights about their profits ${ }^{4}$ and consequently set up new offers for the next session.

\section{Modeling the market with agents}

Given the above defined market setting, students can be replaced by computational agents.

Similarly to students, agents in the model are generators which - based on their cost structures (i.e. marginal cost curves) - create offers for the auction. They also seek for profit maximization. Unlike students, agents behave according to a fixed set of actions and improve their strategic behavior systematically through a defined learning algorithm. This set of actions, however, is developed based on equivalent students' choices. In other words, the range of actions of each agent is made from actions of students who also play the role of this generator. Initially, in the first round, similar to the students, agents offer at their marginal cost curves then update the results and choose actions for the next round. After several rounds, by learning how the previous offering results (the profits they got) are, agents become more "expert" in making offers. At a certain stage, they finally can optimize their strategic behavior.

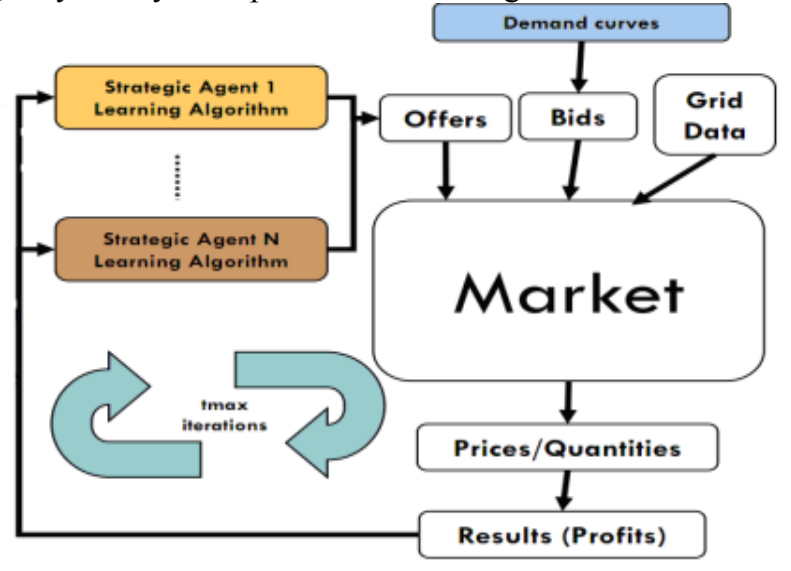

Fig. 3. Process in an agent-based model

In this paper, the modified Roth-Erev Reinforcement Learning algorithm ${ }^{5}$ has been chosen to be the "brain" of agents. The process of thinking, acting and learning of agents in an agent-based model is illustrated in Fig. 3.

\footnotetext{
${ }^{3}$ Details about the mathematical algorithm to solve the problem, refer to [31].

${ }^{4}$ The profit of each generator is calculated simply by deducting their generation cost (equaling their accepted volume multiplied by the equivalent marginal cost) from their total revenue (equaling their accepted volume multiplied by the market clearing price).

${ }^{5}$ For detail explanation of Roth-Erev Reinforcement Learning applied for agentbased modeling, refer to [32]
} 
Actions of agents are defined as a number of mark-up values which agents add to their marginal costs to construct the supply offering curve. In other words, the supply curve of each agent has the same shape as their marginal cost curves but shifted upwards. Every agent chooses a mark-up value based on the goal of profit maximization. In the model of this paper, there are 100 possible actions agents can choose, equivalent to 100 possible mark-up values.

In the set of agent's actions, each action has its own specific probability to be chosen. This probability is changed (or updated) after each market outcomes that agents gain. In the Roth-Erev learning approach, the probability of choice is calculated through the propensity of the action. In general, the probability that an action is chosen over a set of 99 other actions equals to the proportion between this action propensity and the total propensity of all available actions:

$$
p_{i k}(t)=\frac{q_{i k}(t)}{\sum_{k} q_{i k}(t)}
$$

In which:

$p_{i k}(t)$ : probability that agent $\mathrm{i}$ will chose action $\mathrm{k}$ at round $\mathrm{t}$

$q_{i k}(t)$ : propensity of action $\mathrm{k}$ at round $\mathrm{t}$ with agent $\mathrm{i}$

At the initial round, $q_{i k}$ is set based on the parameter "strength of initial propensity" - the scaling parameter $-s(1)$ of the algorithm. After that, $q_{i k}$ is updated after every round. The formula to update $q_{i k}$ requires to know the reward that the agent gains from that round. In this paper, the reward $R$ is defined by comparing the agent's profit of the current round with that of previous round:

$$
R_{k}(t)= \begin{cases}1 & \text { if profit in round } t \text { is larger than profit in round } t-1 \\ 0 & \text { otherwise }\end{cases}
$$

With $R_{k}(t)$ is the reward for agent $i$ of round $t$ in which action $k$ is chosen.

There are two other key parameters of Roth-Erev method which are taken into account for updating $q_{i k}$ : the recency $\theta$ (to slowly reduce the importance of the past experience) and the experimentation $\varepsilon$ (to reinforce actions similar to the current choice).

Combining the 3 parameters, the modified Roth-Erev algorithm in this paper updates the propensity $q_{i k}$ as follows:

$$
q_{i k}(t+1)=(1-\theta) \cdot q_{i k}(t)+E_{j}\left(k, R_{k}(t)\right)
$$

which:

$$
E_{j}\left(k, R_{k}(t)\right)= \begin{cases}(1-\varepsilon) \cdot R_{k}(t) & \text { if } \mathrm{j}=\mathrm{k} \text { (current action) } \\ \frac{\varepsilon}{M-1} \cdot R_{k}(t) & \text { if } \mathrm{j} \neq \mathrm{k} \text { (current action) }\end{cases}
$$

$M$ : total number of available action for agent $i$.

The updated propensity $q_{i k}$ of each action of each agent at each round then leads to the change in the equivalent probability $p_{i k}$ as in (1). That result will affect the agent's choice in the next round. This loop repeats up to a certain point where agents reach their optimal choice of action and the learning process consequently converges.

In order to guarantee an unbiased trend of the model at its initial rounds, the agent-based model is set to run several times. In this paper, the number of runs is chosen to be 5 , and the number of iterations within each run is set to 500 rounds. Results of the model are the average values of these 5 runs.

The founders of the Roth-Erev algorithm found in [26] that the most suitable set of the algorithm's three parameters for their human studies are: Scaling $s(1)=1$, recency $\theta=0.1$ and experimentation $\varepsilon=0.2$. In [10], authors confirmed this set of parameters to be appropriate for their tests. Hence, the agentbased model of this paper also uses these parameter values.

\section{NUMERICAL RESULTS}

In this section, the numerical results of the case study are presented, first for each approach separately and then a comparison of both approaches. In what follows, two approaches are evaluated based on two quantitative indicators of market outcomes: nodal market clearing prices and generators' individual profits.

\section{A. Laboratory sessions' results}

Different sets of students lead to different results. This section presents the average results of 5 lab sessions (the so-called "Lab Average") and the results of 2 individual lab sessions at the KUL in 2008 and 2010 (KUL-08 and KUL-10).

Fig. 4 shows that market clearing prices in lab session KUL10 are the smallest among the three presented results while lab KUL-08 has the largest ones. The gap between both sessions is indeed very large. Price values of the Lab Average are closer to the price levels of lab KUL-10. The explanation for this observation lies in the fact that lab session KUL-08 is an extreme case where the group of students played substantially with their mark-up.

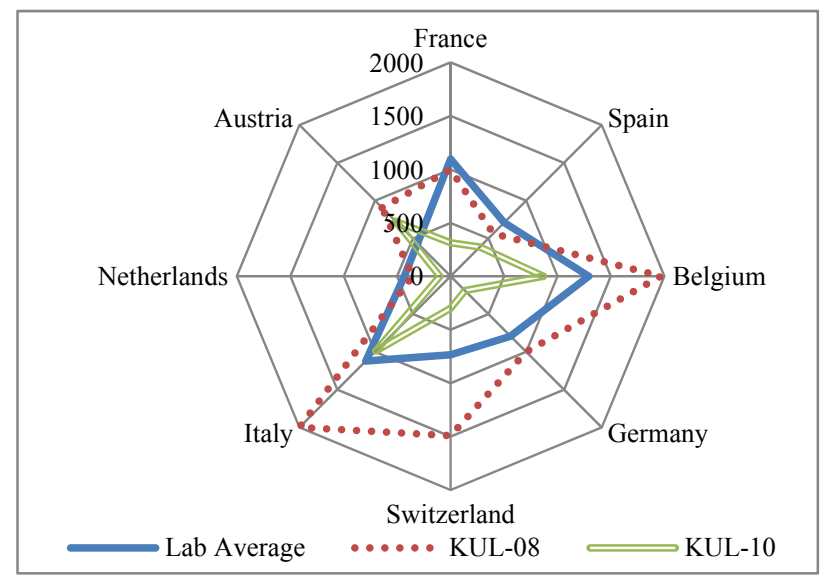

Fig. 4. Market clearing prices of laboratory simulation games

Although the absolute values of prices significantly differ between lab sessions, each individual lab session has its consistent trend of prices. If lab KUL-10 has price levels lower than $1000 \mathrm{EUR} / \mathrm{MWh}$, this trend can be observed for every nodal price. For every node (i.e. country), the market clearing price of this node in lab KUL-10 is always smaller than that of lab KUL-08 (the lab with higher price level). In other words, the results illustrate the students are influenced by their classmates, and learning has been different for different groups of students, with one group clearly outperforming the other groups.

The results in terms of generator profits confirm this observation (see Fig. 5). Individual profits of generators in lab KUL-10 are much smaller than those in lab KUL-08: the 
smallest profits value differs from 61,960 EUR in KUL-10 to 508,843 EUR in KUL-08 and has the value of 624,916 EUR in the Lab Average. The observation about the consistent trend in each lab also persists, i.e. the graph of KUL-08 also completely covers that of KUL-10. In addition, in terms of individual profits, different lab sessions share the same relative ranking of highest/lowest profits among the 14 generators. As illustrated in Fig. 5, a generator like Gen 4 which trades in highly concentrated markets (France) with high market shares $(88 \%)$ always gains the highest profits while Gen1, Gen7 and Gen 13 have much less profits as they are active in less concentrated markets (Germany), and have lower market shares.

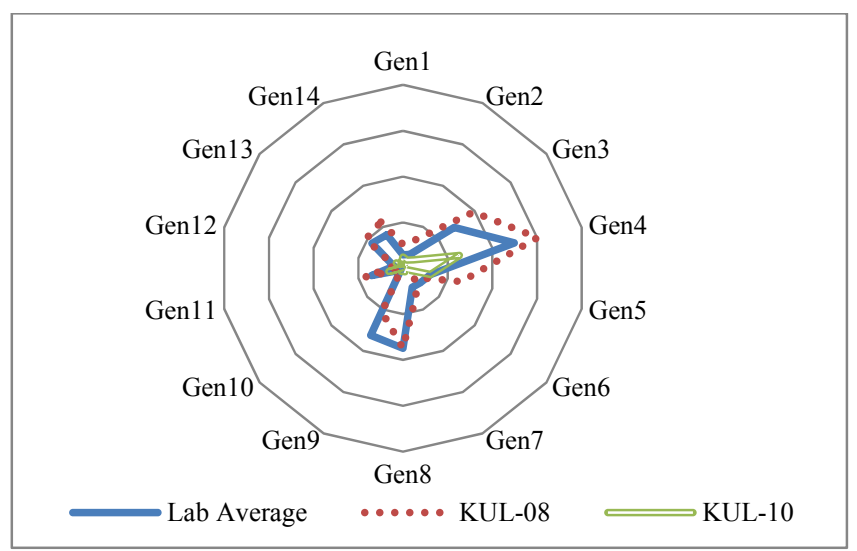

Fig. 5. Generators' profits in laboratory simulation games

\section{B. Agent-based model's results}

Unlike students, agents fine-tune their strategies during many more rounds and then gain the optimal solution for their situation. Agents in our simulation converge after around 100 to 150 rounds.

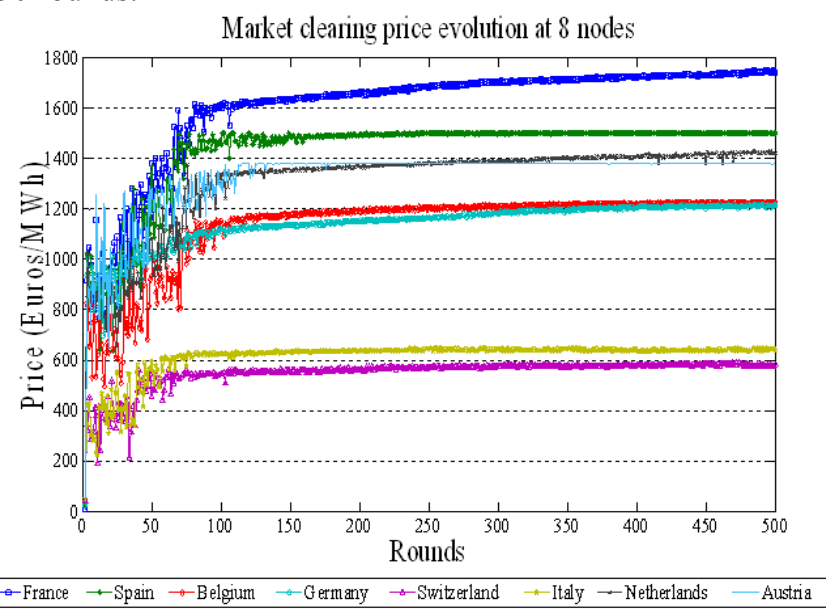

Fig. 6. Market clearing prices evolution of agent-based model

Fig. 6 illustrates the evolution of nodal market clearing prices in the agent-based model (average values of 5 runs). After convergence, the electricity price in France is the highest among nodes and is around $1700 \mathrm{EUR} / \mathrm{MWh}$. The electricity prices in Belgium and Italy - at around $700 \mathrm{EUR} / \mathrm{MWh}$ - are the lowest. It is observable that prices in countries with more concentration (France, Belgium) converge quicker. This can be explained by the fact that in a more competitive market (lower concentration) it is harder for agents to define the optimal strategy as their market power is not strong and the market price is influenced by not only one agent but also by other agents' strategies.

In line with market prices, generators' profits reach the convergent point after 100 to 150 rounds. However, there are large differences between generators' profit values within a market as well as their oscillation ranges before convergence. During the first 150 rounds before convergence, the profit curves of agents which have higher profits fluctuate more strongly than their rivals which have less profit in the same market. The more their profits differ, the clearer this trend is observed.

For example, Fig. 7 above illustrates the evolution of profits of Gen 6 and Gen 12 in the Belgian electricity market. This is a highly concentrated market where Gen 6 predominates over Gen12. Gen6 gains much higher profits than Gen12 and its profit curve swings significantly before convergence at round 150 . Gen12, in contrast, has a pretty stable curve.

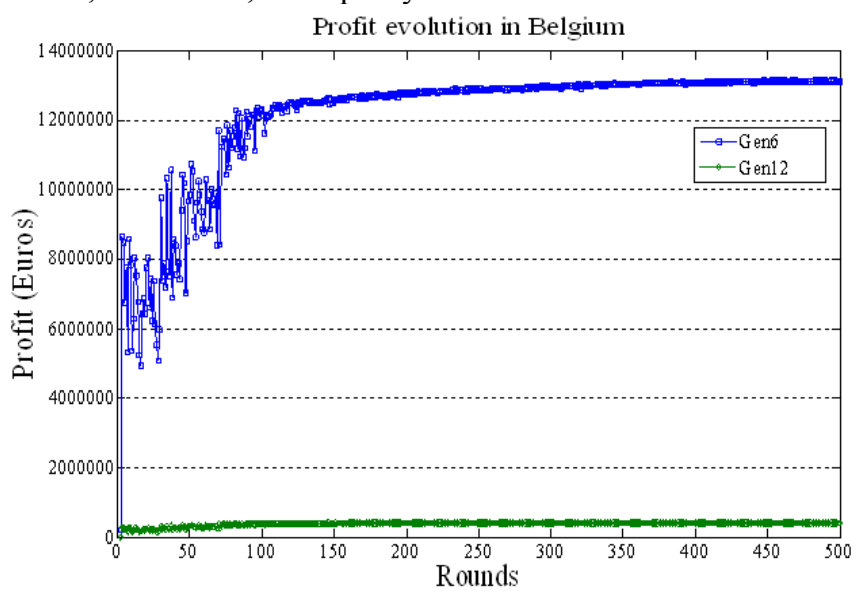

Fig. 7. Individual profit evolution in highly concentrated markets

In less concentrated markets, for example, the Netherlands (see Fig. 8), the same tendency can be observed, although the gap between agents' profit values as well as the difference between their profit curves' oscillation are much smaller than that in highly concentrated markets.

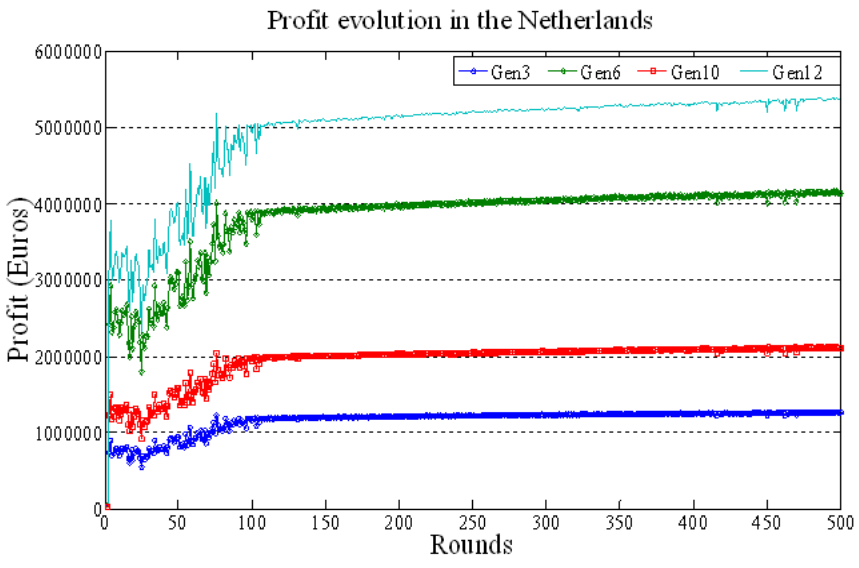

Fig. 8. Individual profit evolution in less concentrated markets

\section{Comparison}

Fig. 9 compares the average market clearing prices in 8 countries of the agent-based simulation with the results of the Lab Average as well as the individual labs KUL-08 and KUL-10. 
Apart from the extreme case of KUL-08, in general, market clearing prices at the 8 nodes of the agent-based model are higher than those of students' experiments. The gaps between prices under the two approaches in these nodes are rather high: 1700 compared to 1097 EUR/MWh in France, or 1323 compared to $437 \mathrm{EUR} / \mathrm{MWh}$ in Austria. In the meantime, in nodes where the prices of the Lab Average are higher than those of the agent-based model (Belgium, Italy), the difference is not that large.

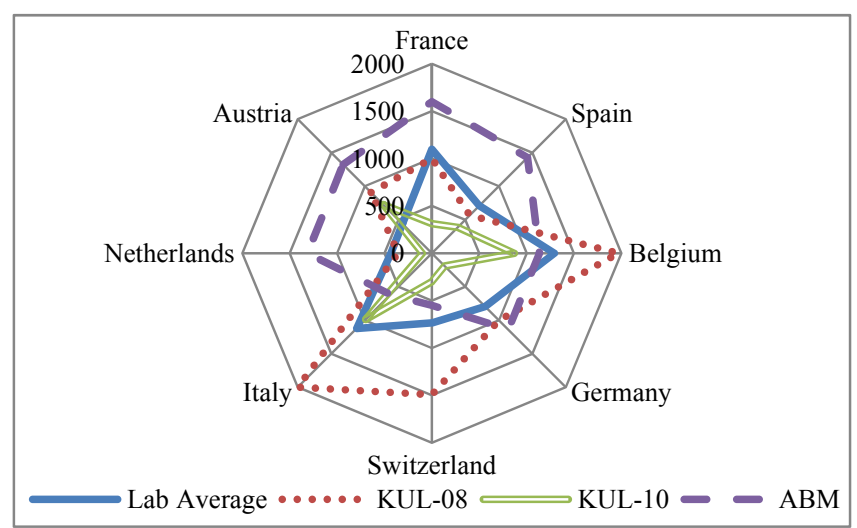

Fig. 9. Price comparison between the two approaches

Unlike prices, the individual profits of generators in the agentbased model completely surpass those of the students' experiments, with a large difference (Fig. 10). Individual profits of every generator as agent are superior to those of generators played by students. Gen4, for example, gets a total profit of 52 million EUR in the agent-based model but only 24 million EUR in the Lab Average or 30 and 12 million EUR in KUL-08 and KUL-10 respectively.

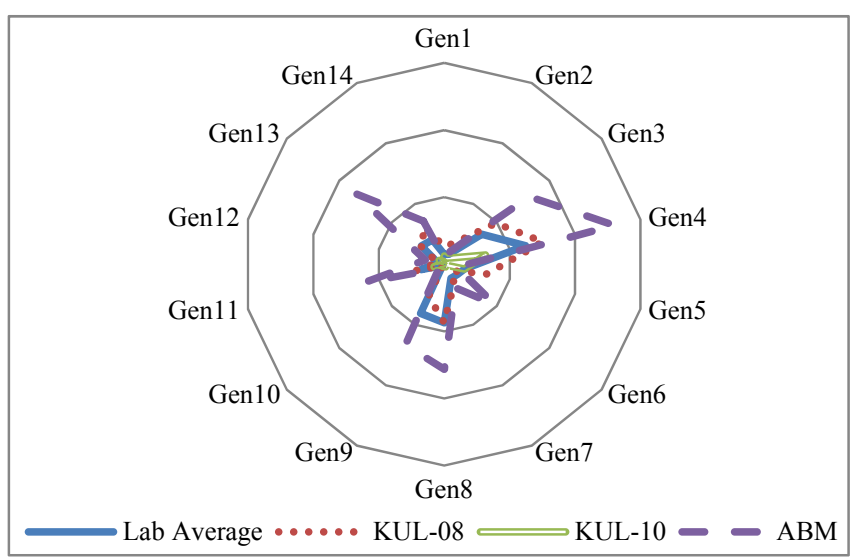

Fig. 10. Individual profits comparison between the two approaches

\section{DISCUSSION}

Quantitative results presented in the previous section shows that computational agents achieved higher generators' profits than students in the given market simulation. It is however difficult to conclude which agent or method is superior. In what follows, we discuss the comparability of the two approaches in the way we have applied them, and we also identify improvements that would need to be made to the market test suite to permit more conclusive comparisons from future experiments.

\section{A. Agents' motivation}

Controlling players' motivation is the most important but challenging task of laboratory experiments. The motivation that an experiment can provide to its human subjects can be intrinsic or extrinsic. Experimental economics literature often stresses the importance of extrinsic motivation using monetary incentives. Gneezy and Rustichini [34] however showed that monetary compensation does not always induce higher performance. If participants perceive the experiment as a monetary environment, their efforts will be determined by the reward. A small payoff can therefore lead to worse performance than no payoff at all. The psychology literature puts even more emphasis on intrinsic motivation. Rydval and Ortmann [35] for instance found that cognitive abilities could be twice as important as financial incentives. Others have warned that money may have detrimental effects on motivation [34]. Educational experiments where students are agents usually use grades as alternative extrinsic incentives while often emphasizing the importance of inducing intrinsic motivation in the simulation games they offer to students [36]-[40]. The intrinsic motivation of students comes from their interests in doing actions which are new and fun to them, and can also come from the element of competition against oneself or others [38].

In this paper, students have been mainly intrinsically motivated to maximize profits in the game. A survey organized by the didactics unit of the university that performed an audit of the game [20] did confirm students' motivation to play the game and learn how to maximize profits during the laboratory sessions. However, when compared to computational agents which are programmed to maximize profits, the motivation of students seems to be uncontrollable and incompatible. As money (i.e. profits) is the incentive of computational agents, a compatible extrinsic incentive should be given to students. Besides grades for the participation, grades proportional to the profit students earned could motivate students as strongly as the profit motivation to real traders. By that means, or by actual payments, the motivation gap between the two approaches could be mitigated.

\section{B. Cognitive issues and expertise}

While agents learn and update their data at a constant rate as they are programmed, humans, in contrast, often have a decreasing rate in their learning function. At a certain point, when knowledge reaches a certain level, learning is slower because it depends on a subjective assessment of efforts and gains, which is difficult to model. According to Hayek [27], this assessment is influenced by time, location, context, personal knowledge, perception, preferences, and other factors. Together they impose cognitive constraints ${ }^{6}$ upon human decision-making process. In addition, when making decisions, individuals and organizations often rely on simple heuristics in an adaptive way and "ignoring part of the information can lead to more accurate judgments than weighting and adding all information" [41]. This is not the case of computational agents which are programmed to make careful decisions based on all information available to them.

\footnotetext{
${ }^{6}$ How cognitive characteristics influence an individual decision-maker are extensively discussed in psychology literature, especially concerning "bounded rationality" [28] and "heuristic decision making" [36].
} 
The results of the KUL lab sessions above provide a clear illustration of the influence of cognitive issues on students' results. There is a large variation between individual sessions and between each of them with the average data. In particular, lab KUL-08 achieves much higher profit results due to the fact that one student started with a very high mark-up, leading all other students to behave similarly (heuristics decision). In addition, results of students in the laboratory are also more fickle than those of computational agents, perhaps explained by the absence of variations in cognitive characteristics in the agentbased model.

Students in the educational laboratory however could not represent the choices by traders in reality due to their lack of expertise. Different groups of students or even different students also have different knowledge and learning speeds which are hard to control for unless a careful selection of participants is made. Computational agents' expertise, in contrast, is more controllable. To compare computational and human agents, a group of selected trading experts might be more uniform and representative of actual trader behavior than students.

\section{Number of rounds and sample size}

Due to limited time resources, our laboratory results include only 5 sessions with a maximum of 15 trading rounds for each. Comparing to 500 rounds of agent-based simulation, that creates a limitation on our comparative illustration and makes it hard to discuss the learning curve of the students.

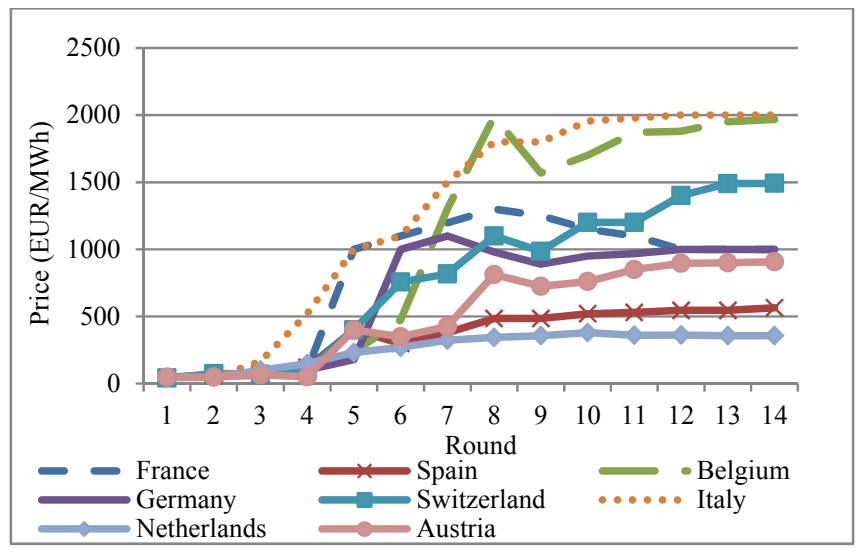

Fig. 11. Convergence of students' laboratory results (market clearing price of lab KUL-08)

The results that we compare are the outcomes that each approach converges to rather than the results they obtain after the same number of rounds, which was typically 100 rounds for computational agents and only 10 rounds for students (Fig. 11). Note however that the quick convergence of students might also be partly explained by inadequate motivation due to the lack of payment.

\section{Freedom of choice}

Freedom of choice is one advantage of the human agents and is hard to model with computational agents who are constrained to a predefined limited "action space". Although our study tried to mitigate this factor by including the full range of students' offers into the agents' action domain, it could have an important impact on the results. Future comparisons need to reduce this inconsistency by either limiting possible choices for the human agents or increasing the action domain of computational agents.

\section{CONCLUSION}

In the market test suite that we designed for students to learn about electricity market design and market behavior, computational agents outperform the groups of students we have had over the years.

The approach used does not allow us to generalize from this result, but the results do illustrate that this is a promising line of research that merits further investigation, and we have identified recommendations for further research.

A first improvement could be to motivate students extrinsically by grading them proportionally to their earned profits in the laboratory sessions, or to make actual monetary payments. Note that the number of rounds in which students trade would then also need to be increased to allow this increased motivation to result in improved learning.

A second improvement could be to align better the action domain of students with that of agents, which could be done by reducing the action domain of students in the market test suite we developed.

\section{ACKNOWLEDGMENTS}

This paper has benefited from comments by the editor, and three anonymous referees. The authors would also like to thank their colleagues: C. De Jonghe, E. Delarue, J. Tant, K. De Vos, K. Purchala, K. Verhaegen, L. Vandezande, P. Buijs and T. Meersseman of the KU Leuven for helping with the organization of the simulation lab games in recent years.

\section{REFERENCES}

[1] A. Papalexopoulos, "Lessons learned from past electricity market design models and a road map for the next generation design models," Panel Presentation in Panel Session: Next-Generation Electricity Market Models, and Regulatory Developments, 2006 IEEE Power Engineering Society General Meeting, Jun. 2006.

[2] A. E. Roth, "The economists as engineer: Game theory, experimentation, and computation as tools for design economics," Econometrica, vol. 70, no. 4, pp. 1341-1378, July 2002 .

[3] B. F. Hobbs, "Linear complementarity models of Nash-Cournot competition in bilateral and POOLCO power markets," IEEE Trans. Power Syst., vol. 16, no. 2, pp. 194-202, May 2001.

[4] R. W. Ferrero, S. M. Shahidehpour, and V. C. Ramesh, "Transaction analysis in deregulated power systems using game theory," IEEE Trans. Power Syst., vol. 12, no. 3, pp. 1340-1347, Aug. 1997.

[5] J. B. Cardell, C. C. Hitt, and W. W. Hogan, "Market power and strategic interaction in electricity networks," Resource \& Energy Economics, vol. 19, issue 1-2, pp. 109-137, Mar. 1997.

[6] F. Milano, C. A. Canizares, and A. J. Conejo, "Sensitivity-based securityconstrained OPF market clearing model," IEEE Trans. Power Syst., vol. 20, no. 4, pp. 2051-2060, Nov. 2005.

[7] K. Neuhoff, J. Barquin, M. G. Boots, A. Ehrenmann, B. F. Hobbs, F. A. M. Rijkers, and M. Vázquez, "Network-constrained Cournot models of liberalized electricity markets: the devil is in the details," Energy Economics, vol. 27, issue 3, pp. 495-525, May 2005.

[8] R. Baldick, "Computing the Electricity Market Equilibrium: Uses of Market Equilibrium Models," in Restructured Electric Power Systems (ed X.-P. Zhang), John Wiley \& Sons, Inc., Hoboken, NJ, USA, 2010.

[9] M. Ventosa, A. Baíllo, M. Rivier, and A. Ramos, "Electricity Market Modeling Trends," Energy Policy, vol. 33, issue 7, pp. 897-913, May 2005.

[10] A. Weidlich and D. Veit, "A critical survey of agent-based wholesale electricity market models," Energy Economics, vol. 30, issue 4, pp. $1728-1759$, July 2008. 
[11] A. Weidlich and D. Veit, "Bidding in Interrelated Day-ahead Electricity Markets - Insights from an Agent-based Simulation Model," in Proceedings of the $29^{\text {th }}$ IAEE International Conference, Potsdam, 2006.

[12] D. W. Bunn and F. S. Oliveira, "Evaluating individual market power in electricity markets via agent-based simulation," Annals of Operations Research, vol. 121, no. 1-4, pp. 55-77, 2003

[13] A. Weidlich and D. Veit, "Analyzing Interrelated Markets in the Electricity sector - The case of Wholesale Power Trading in Germany," IEEE Power and Energy Society General Meeting - Conversion and Delivery of Electrical Energy in the 21st Century, Pittsburgh, PA, USA, 20-24 July, 2008.

[14] Th. Krause, "Evaluating Congestion Management Schemes in Liberalized Electricity Markets Applying Agent-based Computational Economics," Phd dissertation, Swiss Federal Institute of Technology Zurich, 2007. Available at http://www.eeh.ee.ethz.ch/

[15] A. Weidlich, "Engineering Interrelated Electricity Markets - An AgentBased Computational Approach," Physica-Verlag, Springer Publication, 2008.

[16] P. Visudhiphan, "An agent-based approach to modeling electricity spot markets," Unpublished doctoral dissertation, Massachusetts Institute of Technology, 2003.

[17] J. Nicolaisen, M. Smith, V. Petrov, and L. Tesfatsion, "Concentration and capacity effects on electricity market power, "Proceedings of the 2000 Congress on Evolutionary Computation, vol. 2, pp. 1041-1047, La Jolla, USA, 2000.

[18] J. Sun and L. Tesfatsion, "An Agent-based Computational Laboratory for Wholesale Power Market Design," Staff General Research Papers 12776 , Iowa State University, Department of Economics, Jan. 2007.

[19] J. Contreras, A. J. Conejo, S. de la Torre, M. G. Munoz, "Power engineering lab: Electricity market simulator," IEEE Trans. Power Syst., vol. 17, no. 2, pp. 223-228, May 2002.

[20] E. Delarue, E. Laga, L. Meeus, R. Belmans, and W. D'haeseleer, "Achieving learning potentials in an educational simulation game for trading and generating electrical energy," International Journal of Engineering Education, vol. 27, no. 4, pp. 703-712, 2011.

[21] C. Staropoli and C. Jullien , "Using Laboratory Experiments to Design Efficient Market Institutions, The case of wholesale electricity markets," Annals of Public and Cooperative Economics, C. Staropoli and A. Yvrande-Billon Eds, vol. 77, no. 4, Dec. 2006.

[22] S. J. Rassenti, V. L. Smith, and B. J. Wilson, "Using experiments to inform the privatization/ deregulation movement in electricity," Cato Journal, vol. 21, no. 3, pp. 515-544, Winter 2002.

[23] M. Saguan, N. Keseric, P. Dessante, and J.-M. Glachant, "Market Power in Power Markets: Game Theory vs. Agent-based Approach," IEEE PES Transmission and Distribution Conference and Exposition Latin America, Venezuela, 2006.

[24] Th. Krause, G. Andersson, D. Ernst, E.V. Beck, R. Cherkaoui and A. Germond, "A comparison of Nash equilibria analysis and agent-based modelling for power markets," International Journal of Electrical Power \& Energy Systems, vol. 28, issue 9, pp. 599-607, Nov. 2006.

[25] J. Duffy, "Chapter 19: Agent-based models and human subject experiments," Handbook of Computational Economics, vol. 2, pp. 949-1011, 2006.

[26] I. Erev and A. E. Roth, "Predicting how people play games: Reinforcement learning in experimental games with unique, mixedstrategy equilibria," American Economic Review, vol. 88, issue 4, 1998.

[27] F. A. Hayek, "The use of knowledge in Society," American Economic Review, vol. 35, issue 4, Sep. 1945.

[28] H. A. Simon, "Theories of bounded rationality," Chapter 8 in C. B. McGuire and R. Radner (Eds.), Decision and Organization, Amsterdam: North-Holland, 1972.

[29] European Commission, "DG Competition report on energy sector inquiry," SEC(2006)1724, 10th January, 2007. Available at http://ec.europa.eu/competition/

[30] L. Meeus, L. Vandezande, S. Cole, and R. Belmans, "Market coupling and the importance of price coordination between power exchanges," Energy, vol. 34, issue 3, pp. 228-234, 2009.

[31] L. Meeus, T. Meersseman, K. Purchala, and R. Belmans, "Market coupling simulator," IEEE Power Engineering Society General Meeting, San Francisco, California, USA, 7 pages, June 12-16, 2005.

[32] L. Tesfatsion, "Agent-based computational economics: A constructive approach to economic theory". In L. Tesfatsion \& K. L. Judd (Eds.),
Handbook of computational economics, volume 2: Agent-based computational economics, Amsterdam: North-Holland, 2006.

[33] L. Meeus, "Power Exchange auction trading platform design," Phd dissertation, Dept. Elect. Eng., K.U.Leuven, 2006. Available at http://www.esat.kuleuven.be/

[34] U. Gneezy and A. Rustichini, "Pay enough - or don't pay at all," Quarterly Journal of Economics, vol. 115, issue 3, pp. 791-811, August 2000.

[35] O. Rydval and a. Ortmann, "How financial incentives and cognitive abilities affect task performance in laboratory settings: an illustration," Economics Letters, vol. 85, pp. 315-320, August 2004.

[36] D. J. Stipek, "Motivation to learn: From theory to practice (3rd ed.)," Boston: Allyn \& Bacon, 1998.

[37] R. Garris, R. Ahlers, and J. E. Driskell, "Games, motivation, and learning: A research and practice model," Simulation \& Gaming: An Interdisciplinary Journal, vol. 33, no. 4, pp. 441-467, Dec. 2002.

[38] H. H. Wideman, R. D. Owston and C. Brown, "Unpacking the potential of educational gaming: a new tool for gaming research," Simulation \& Gaming, vol. 38, no.1, pp. 46-54, Mar. 2007.

[39] J. D. Bransford, A. L. Brown, and R. R. Cocking, "How people learn: Brain, Mind, Experience, and School (expanded ed.)," Nat. Acad. Press: Washington, DC, 2000.

[40] R. Z. Enciso, "Simulation games, a learning tool," Proceedings of the International Simulation and Gaming Association Conference, Bari, Italy, Sep. 2001.

[41] G. Gigerenzer and W. Gaissmaier, "Heuristic decision making," Annual Review of Psychology, vol. 62, pp. 451-482, 2011.

[42] L. Meeus and M. Saguan, "Experience with market test suite to simulate imperfect competitive behavior in electricity markets," presented at the Conf. Models for Electricity Generation Strategy in the 21st Century: New roles and new approaches, Madrid, Sep. 2008.

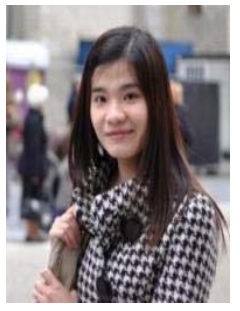

Quynh Chi Trinh received the M.S. degree in Economics and Management of Network Industries in 2008 from Delft University of Technology and University of Paris XI (Erasmus Mundus scholarship). She is a member of the KU Leuven Energy Institute and of the Electrical Energy research group (ELECTA) of the department of Electrical Engineering of the K.U Leuven, where she is working towards a Ph.D. on electricity market design. Her research interests include policy, economic aspects of power systems, electricity markets and security of supply.

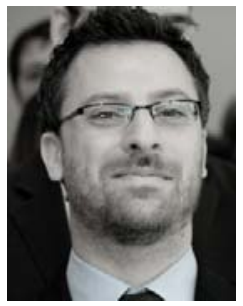

Marcelo Saguan Marcelo Saguan is a senior consultant in Economics and leads the Energy \& Climate Practice at Microeconomix. Marcelo was previously Jean Monnet Fellow at the RSCAS in the Loyola de Palacio Energy Policy Programme. He had a postdoctoral position at University of Paris XI. He holds a PhD in Energy Economics (2007) from the University of Paris XI and the Ecole Supérieure d'Electricité (Supélec) and Master Degrees in Industrial Engineering from ENIM (Metz) and from the University of Cuyo, Argentina (2001)

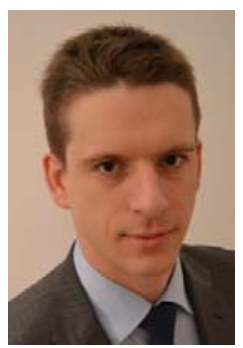

Leonardo Meeus is research fellow at the Florence School of Regulation in the European University Institute in Italy, and visiting professor at the KU Leuven in Belgium. Leonardo is the scientific coordinator of the EU FP7 funded research project THINK that advises the European Commission (DG Energy) on energy policy (2010-13). He was the scientific coordinator of the Florence School of Regulation (2008-09) and of the European Energy Institute at the KU Leuven (2006-08). He also worked in Ireland, heading regulatory affairs for an electricity interconnector developer (2008-09). Dr. Meeus is a commercial engineer (2002) with a $\mathrm{PhD}$ in electrical engineering (2006), both from the KU Leuven in Belgium. 